\title{
Risk factors for shunt malfunction in pediatric hydrocephalus: a multicenter prospective cohort study
}

\author{
Jay Riva-Cambrin, MD, MSc, ${ }^{1}$ John R. W. Kestle, MD, ${ }^{1}$ Richard Holubkov, PhD, ${ }^{2}$ Jerry Butler, MSc, ${ }^{2}$ \\ Abhaya V. Kulkarni, MD, PhD, ${ }^{3}$ James Drake, MBBCh, MSc, ${ }^{3}$ William E. Whitehead, MD, ${ }^{4}$ \\ John C. Wellons III, MD, MSPH, ${ }^{5}$ Chevis N. Shannon, MBA, MPH, DrPH, ${ }^{5}$ \\ Mandeep S. Tamber, MD, PhD, ${ }^{6}$ David D. Limbrick Jr., MD, PhD, ${ }^{7}$ Curtis Rozzelle, MD, ${ }^{8}$ \\ Samuel R. Browd, MD, PhD, ${ }^{9}$ and Tamara D. Simon, MD, MSPH, ${ }^{10}$ for the Hydrocephalus Clinical \\ Research Network
}

${ }^{1}$ Division of Pediatric Neurosurgery, Department of Neurosurgery, Primary Children's Hospital, University of Utah; ${ }^{2}$ Department of Pediatrics, University of Utah, Salt Lake City, Utah, ${ }^{3}$ Division of Neurosurgery, Hospital for Sick Children, University of Toronto, Ontario, Canada; ${ }^{4 D}$ ivision of Pediatric Neurosurgery, Texas Children's Hospital, Department of Neurosurgery, Baylor College of Medicine, Houston, Texas; ${ }^{5}$ Department of Neurosurgery, Vanderbilt University, Nashville, Tennessee; ${ }^{6}$ Division of Pediatric Neurosurgery, University of Pittsburgh, Pennsylvania; ${ }^{7}$ Division of Pediatric Neurosurgery, Washington University, St. Louis, Missouri; ${ }^{8}$ Section of Pediatric Neurosurgery, Children's Hospital of Alabama, Division of Neurosurgery, University of AlabamaBirmingham, Alabama; and Departments of ${ }^{~}$ Neurosurgery and ${ }^{10}$ Pediatrics, University of Washington/Seattle Children's Hospital, Seattle, Washington

OBJECTIVE The rate of CSF shunt failure remains unacceptably high. The Hydrocephalus Clinical Research Network (HCRN) conducted a comprehensive prospective observational study of hydrocephalus management, the aim of which was to isolate specific risk factors for shunt failure.

METHODS The study followed all first-time shunt insertions in children younger than 19 years at 6 HCRN centers. The HCRN Investigator Committee selected, a priori, 21 variables to be examined, including clinical, radiographic, and shunt design variables. Shunt failure was defined as shunt revision, subsequent endoscopic third ventriculostomy, or shunt infection. Important a priori-defined risk factors as well as those significant in univariate analyses were then tested for independence using multivariate Cox proportional hazard modeling.

RESULTS A total of 1036 children underwent initial CSF shunt placement between April 2008 and December 2011. Of these, 344 patients experienced shunt failure, including 265 malfunctions and 79 infections. The mean and median length of follow-up for the entire cohort was 400 days and 264 days, respectively. The Cox model found that age younger than 6 months at first shunt placement (HR 1.6 [95\% Cl 1.1-2.1]), a cardiac comorbidity (HR 1.4 [95\% Cl 1.0-2.1]), and endoscopic placement (HR 1.9 [95\% Cl 1.2-2.9]) were independently associated with reduced shunt survival. The following had no independent associations with shunt survival: etiology, payer, center, valve design, valve programmability, the use of ultrasound or stereotactic guidance, and surgeon experience and volume.

CONCLUSIONS This is the largest prospective study reported on children with CSF shunts for hydrocephalus. It confirms that a young age and the use of the endoscope are risk factors for first shunt failure and that valve type has no impact. A new risk factor-an existing cardiac comorbidity - was also associated with shunt failure.

http://thejns.org/doi/abs/10.3171/2015.6.PEDS14670

KEY WORDS hydrocephalus; pediatric; risk factors; prospective; CSF shunt; Hydrocephalus Clinical Research Network

ABBREVIATIONS AIC = antibiotic-impregnated catheter; $\mathrm{CCC}=$ complex chronic conditions; $\mathrm{DCC}=$ data coordinating center; FOHR $=$ frontal and occipital horn ratio; HCRN = Hydrocephalus Clinical Research Network; IRB = institutional review board; IVH = intraventricular hemorrhage.

ACCOMPANYING EDITORIAL See pp 379-381. DOI: 10.3171/2015.7.PEDS15375.

SUBMITTED November 25, 2014. ACCEPTED June 17, 2015.

INCLUDE WHEN CITING Published online December 4, 2015; DOI: 10.3171/2015.6.PEDS14670. 
$\mathrm{H}$ YDROCEPHALUS in the pediatric population levies significant clinical and economic tolls on both the health care system and the affected patients and families. Most of this morbidity is represented by subsequent reevaluations, readmissions, and procedures associated with CSF shunt revisions and infections. ${ }^{20}$

For decades, the pediatric neurosurgical community has aimed to minimize CSF shunt failure, which is defined as either a CSF shunt malfunction requiring revision or a CSF shunt infection. Attempts to identify specific risk factors for shunt failure have been reported previously for both shunt malfunction ${ }^{1,2,5,17,21,23}$ and shunt infection. ${ }^{6-8,10,12,16,19,22}$ Development of new adjuncts, such as the use of the ultrasound and frameless stereotaxy, ${ }^{14,24}$ and new CSF shunt hardware, such as antibiotic-impregnated catheters (AICs), ${ }^{16}$ have also been examined. These incremental discoveries may explain the improvement in CSF shunt survival from a multicenter composite 1990s cohort to a modern 2007-2012 cohort reported by Kulkarni et al. ${ }^{13}$

The best evidence, in terms of investigating factors associated with CSF shunt survival, comes from the Shunt Design Trial ${ }^{3}$ and the Endoscopic Shunt Insertion Trial, ${ }^{9}$ which demonstrated that neither various valve designs nor the use of the endoscope improved shunt survival. Subsequent studies have examined factors influencing CSF shunt failure, although many (but not all) of these studies suffer from being retrospective, $2,5,7,8,14,16,17,19,21,22,24$ from a single center, ${ }^{1,2,5-8,12,14,16,17,21-24}$ or a heterogeneous mixture of new insertions and revision procedures. ${ }^{1,6,7,10,12,14,16,17,23,24}$ Therefore, it is perhaps not surprising that many of these studies have suggested contradictory findings in terms of variables associated with CSF shunt failure. This is particularly apparent when age $\mathrm{e}^{7,17,21,23}$ and etiology of the hydrocephalus $\mathrm{s}^{2,17,21,23}$ are specifically examined.

The objective of this study was to determine the independent risk factors for CSF shunt failure (malfunction and infection) in children undergoing their first shunt insertion for hydrocephalus. This multicenter prospective cohort study was conducted by the Hydrocephalus Clinical Research Network (HCRN), a 9-center collaborative group focused on improving the lives of children with hydrocephalus through epidemiological investigations of clinical outcomes.

\section{Methods \\ Study Population}

Inclusion criteria for this multicenter prospective cohort study were as follows. The patients had to be children younger than 19 years of age undergoing their first insertion of a CSF shunt for treatment of hydrocephalus. All children were consecutively identified at one of the 6 participating HCRN centers between April 23, 2008, and December 31, 2011, and were followed up prospectively until study closure on December 31, 2011. The participating HCRN centers for this specific study were the University of Utah/Primary Children's Hospital, the University of Alabama in Birmingham/Children's Hospital of Alabama, the University of Washington/Seattle Children's Hospital, the Washington University/St. Louis Children's
Hospital, the Baylor School of Medicine/Texas Children's Hospital, and the University of Toronto/The Hospital for Sick Children.

Patients were excluded if they underwent insertion of a subdural-peritoneal shunt for the treatment of subdural hematomas. However, patients who underwent the insertion of a subdural-peritoneal shunt for subdural hygromas in the setting of hydrocephalus were included.

\section{Data Collection and Management}

The study was approved by the Investigator Committee of the HCRN and by the institutional review board (IRB)/ research ethics board at each site as well as the Data Coordinating Center (DCC) at the University of Utah. A waiver of consent was authorized at all but one site, at which each patient's family gave informed consent to enter the study.

Upon enrollment, each patient's data were collected in a prospective manner in the operating room, clinic, or ward by a trained HCRN data coordinator at each site. The data were uploaded in a secure, de-identified fashion to the centralized DCC and were subject to both on-site and remote data monitoring.

\section{Primary Study Outcome}

The study's primary outcome was time to the first CSF shunt failure. Shunt failure was a composite outcome defined as either CSF shunt malfunction or CSF shunt infection. Shunt malfunction was further defined as the need for a subsequent shunt surgery including a CSF shunt revision or removal of the shunt in conjunction with a successful endoscopic third ventriculostomy. Shunt infection was defined as one of the following: 1) identification of organisms on Gram stain or culture from CSF, wound swab, or pseudocyst; 2) shunt erosion (defined as wound breakdown with visible shunt hardware); 3) abdominal pseudocyst (even in the absence of positive cultures); or 4) positive blood culture in the presence of a ventriculoatrial shunt. ${ }^{10}$ This composite definition of time to shunt failure is consistent with the published literature, namely the Shunt Design Trial ${ }^{3}$ and the Endoscopic Shunt Insertion Trial. ${ }^{9}$

\section{Demographic Variables}

Demographic variables examined in the study included age (dichotomized as 6 months of age or younger at CSF shunt insertion versus older than 6 months), sex, race/ethnicity, HCRN site, and insurance or payer (i.e., private insurance, public insurance, or self-pay/other). The age cutoff of 6 months was chosen by consensus among HCRN investigators after considering previous unpublished data from a smaller HCRN data set; it was also recognized that the cutoff of 6 months split the cohort evenly $(55.7 \%$ were 6 months old or younger).

\section{Clinical Variables}

The etiology of hydrocephalus was prospectively assigned by the treating pediatric neurosurgeon prior to shunt placement and analyzed as one of the following mutually exclusive categories: post-intraventricular hemorrhage (IVH) secondary to prematurity, myelomeningocele, aq- 
ueductal stenosis, posterior fossa tumor, other intracranial tumor, congenital communicating, postinfectious, posthead injury, and other. We also recorded whether the patient had a gastrostomy or tracheostomy tube prior to CSF shunt insertion. Patient comorbidities at the time of initial shunt placement were recorded using the complex chronic conditions (CCC) method, which has been validated in the pediatric population. ${ }^{4}$ The number of system comorbidities or CCCs were summed for each patient and analyzed as a category with 3 tiers $(0,1$, or $\geq 2$ CCCs). The neuromuscular and cardiac CCCs were analyzed as independent categories. Specifically, a cardiac CCC includes heart and great vessel malformations, cardiomyopathies, and conduction disorders and dysrhythmias. Neuromuscular CCC was modified to exclude hydrocephalus for more meaningful analysis in our exclusively hydrocephalic cohort as previously described..$^{20}$ Preoperative or preshunt ventricle size was used as a proxy for the severity of hydrocephalus. It was measured from preoperative ultrasound, CT, or MRI using the validated frontal and occipital horn ratio (FOHR). ${ }^{11,15}$

\section{Surgical Variables}

Three surgical adjuncts for intraoperative proximal catheter placement were examined: the use of the intraoperative ultrasound, the use of a CSF shunt endoscope, and the use of frameless stereotaxy. Data for the use of frameless stereotaxy were only collected beginning in January 2011, and therefore there are a significant number of "Unknowns" prior to that date. Surgeon experience was defined as the number of years of independent clinical practice at the time of the CSF shunt insertion. Surgeon volume was defined as the specific surgeon's total number of initial CSF shunt insertions per year during the period of study. Surgical case duration was recorded in minutes, and case priority was dichotomized as either elective or an add-on or an emergency (i.e., outside of scheduled operating room time). The location of the proximal catheter was listed as intraventricular or in a subdural hygroma or a cyst. Finally, in all but 3 patients (atrial), the distal catheter was placed within the peritoneum and the peritoneal entry method technique was recorded as trocar, laparoscopic, mini-lap, or unknown.

\section{CSF Shunt Hardware Variables}

The manufacturer and specific type of CSF shunt valve placed during the initial shunting procedure were reported to and analyzed by the DCC in a blinded fashion. CSF shunt valves were also categorized by whether they were fixed or programmable as described by each manufacturer. An initial CSF shunt catheter was categorized as being an AIC if some or all of the shunt catheters used in the procedure were AIC.

\section{Statistical Analyses}

Continuous variables were reported as either means with SDs or medians and interquartile ranges (IQRs). Dichotomous and categorical variables were reported using frequencies and percentages. Each variable was compared with the primary outcome of time to first CSF shunt failure in a univariate fashion using survival analyses, and the results were presented as hazard ratios and their corresponding $95 \%$ confidence intervals.

Statistically significant variables $(\mathrm{p}<0.05)$ with univariate analyses were included in the multivariate Cox proportional hazard model. We decided a priori to include the following variables in the multivariate model independent of the univariate results: hydrocephalus etiology (because previous literature supported its association with shunt failure ${ }^{21,23}$ ), HCRN site (to adjust for potential unidentified confounders associated with variability of care), ventricle size (FOHR) (as a risk adjustment for severity of hydrocephalus), and shunt programmability. It was also decided a priori that if either the valve manufacturer or the programmability variable was associated with shunt failure on univariate analyses then both variables would be tested in the multivariate analysis. Similarly, we decided a priori not to include race in the multivariate model because one site's IRB denied permission to collect race data and the significant complement was the "Other/Unknown" category. The multivariate Cox proportional hazard model was built using stepwise methodology with the criterion for variable entry into the model being $p \leq 0.05$ and the criterion for removal being $p>0.05$. The final multivariate results were presented as hazard ratios and their associated confidence intervals. The proportional hazard assumption was tested for all variables, and no time dependence was identified.

All analyses were performed using SAS (version 9.2, SAS Institute).

\section{Results}

\section{Description of the Overall HCRN Cohort}

We enrolled 1036 children in whom initial CSF shunts were placed at the 6 participating HCRN centers between April 23, 2008, and December 31, 2011, and prospectively monitored them until study closure on December 31, 2011. The mean length of follow-up for the entire cohort was 400 days (380 days SD), while the median length of follow-up was 264 days (IQR 68-691 days). The cohort's mean age was $131 \pm 228$ weeks; $56 \%$ of these children had their initial CSF shunt placed within the first 6 months of age (Table 1). The most common underlying etiologies for hydrocephalus were post-IVH due to prematurity (22\%), myelomeningocele $(16 \%)$, posterior fossa tumors $(11 \%)$, and aqueductal stenosis (8\%) (Table 1). The "Other" category included etiologies such as spontaneous IVH (nonprematurity), intracranial cysts, congenital malformations, Dandy-Walker syndrome, and craniosynostosis. The majority $(70 \%)$ of the children had no other comorbidities (CCCs), but $11 \%$ had a neuromuscular CCC (other than hydrocephalus) and $8 \%$ had a cardiac CCC.

For these initial CSF shunt insertions, the vast majority of proximal catheters $(93 \%)$ were intraventricular and almost all of the distal catheters (99.7\%) were peritoneal; $11 \%$ of all catheters were AICs. Surgeons placed a programmable valve as the original CSF shunt system in 17\% of cases. In terms of surgical adjuncts, intraoperative ultrasound was used in $26 \%$ of cases, the endoscope in $32 \%$ of cases, and frameless stereotaxy in 5\% of the most recent cases. 
TABLE 1. Variables describing the HCRN study cohort

\begin{tabular}{|c|c|}
\hline Variable & $\begin{array}{l}\text { Study Cohort } \\
(n=1036)^{*}\end{array}$ \\
\hline \multicolumn{2}{|l|}{ Demographics } \\
\hline Age 0-6 mos & $577(55.7)$ \\
\hline Male sex & $582(56.2)$ \\
\hline \multicolumn{2}{|l|}{ Race } \\
\hline White & $655(63.2)$ \\
\hline African American & $152(14.7)$ \\
\hline Asian & $20(1.9)$ \\
\hline $\mathrm{NH} / \mathrm{PI} / \mathrm{Al} / \mathrm{AN}$ & $10(1.0)$ \\
\hline Other/unknown & $199(19.2)$ \\
\hline \multicolumn{2}{|l|}{ Insurance } \\
\hline Public & $570(55.0)$ \\
\hline Private & $409(39.5)$ \\
\hline Other/self-pay & $57(5.5)$ \\
\hline \multicolumn{2}{|l|}{ HCRN site } \\
\hline 1 & $254(24.5)$ \\
\hline 2 & $149(14.4)$ \\
\hline 3 & $277(26.7)$ \\
\hline 4 & $224(21.6)$ \\
\hline 5 & $96(9.3)$ \\
\hline 6 & $36(3.5)$ \\
\hline \multicolumn{2}{|l|}{ Clinical factors } \\
\hline \multicolumn{2}{|l|}{ Hydrocephalus etiology } \\
\hline Post-IVH due to prematurity & $226(21.8)$ \\
\hline Myelomeningocele & $164(15.8)$ \\
\hline Aqueductal stenosis & $84(8.1)$ \\
\hline Posterior fossa tumor & $109(10.5)$ \\
\hline Tumor, other & $83(8.0)$ \\
\hline Congenital communicating & $80(7.7)$ \\
\hline Postinfectious & $38(3.7)$ \\
\hline Post-head injury & $49(4.7)$ \\
\hline Other & $203(19.6)$ \\
\hline Mean preop FOHR† & $0.55 \pm 0.13$ \\
\hline Gastrostomy tube & $100(9.7)$ \\
\hline Tracheostomy & $29(2.8)$ \\
\hline \multicolumn{2}{|l|}{ No of CCCs } \\
\hline 0 & $727(70.2)$ \\
\hline 1 & $247(23.8)$ \\
\hline$\geq 2$ & $62(6.0)$ \\
\hline Neuromuscular CCC & $115(11.1)$ \\
\hline Cardiac CCC & $83(8.0)$ \\
\hline \multicolumn{2}{|l|}{ Surgeon factors } \\
\hline \multicolumn{2}{|c|}{ Surgeon experience at time of shunt placement } \\
\hline$<5$ yrs & $229(22.1)$ \\
\hline $5-9$ yrs & $361(34.9)$ \\
\hline$\geq 10 \mathrm{yrs}$ & $446(43.1)$ \\
\hline \multicolumn{2}{|c|}{ Surgeon vol at time of shunt placement } \\
\hline$<10$ new shunts/yr & $88(8.5)$ \\
\hline 10-19 new shunts/yr & $624(60.2)$ \\
\hline$\geq 20$ new shunts/yr & $324(31.3)$ \\
\hline \multicolumn{2}{|l|}{ Use of frameless stereotaxy } \\
\hline Yes & $49(4.7)$ \\
\hline No & $287(27.7)$ \\
\hline Unknown & $700(67.6)$ \\
\hline
\end{tabular}

TABLE 1. Variables describing the HCRN study cohort (continued)

\begin{tabular}{|c|c|}
\hline Variable & $\begin{array}{l}\text { Study Cohort } \\
(n=1036)^{*}\end{array}$ \\
\hline \multicolumn{2}{|l|}{ Surgeon factors (continued) } \\
\hline Use of endoscope & $271(26.2)$ \\
\hline Use of ultrasound & $335(32.3)$ \\
\hline \multicolumn{2}{|l|}{ Shunt hardware } \\
\hline \multicolumn{2}{|l|}{ Shunt manufacturers } \\
\hline A & $433(41.8)$ \\
\hline B & $363(35.0)$ \\
\hline C & $98(9.5)$ \\
\hline D & $72(7.0)$ \\
\hline $\mathrm{E}$ & $36(3.5)$ \\
\hline Other & $34(3.3)$ \\
\hline \multicolumn{2}{|l|}{ Shunt programmability } \\
\hline Programmable & $177(17.1)$ \\
\hline Fixed & $845(81.6)$ \\
\hline Other/unknown/no valve & $14(1.4)$ \\
\hline AIC & $118(11.4)$ \\
\hline \multicolumn{2}{|l|}{ Other surgical factors } \\
\hline Ventricular proximal catheter & $968(93.4)$ \\
\hline \multicolumn{2}{|l|}{ Peritoneal entry method $\ddagger$} \\
\hline Minilap & $589(57.0)$ \\
\hline Laparoscopic & $24(2.3)$ \\
\hline Trocar & $362(35.0)$ \\
\hline Not documented & $58(5.6)$ \\
\hline Mean case duration in mins & $57 \pm 31$ \\
\hline Add-on/emergency case priority & $383(37.0)$ \\
\hline \multicolumn{2}{|c|}{$\begin{array}{l}\mathrm{Al}=\text { American Indian; } \mathrm{AN}=\text { Alaskan Native; minilap = mini-open laparotomy; } \\
\mathrm{NH}=\text { Native Hawaiian; } \mathrm{PI}=\text { Pacific Islander. } \\
\text { * Values are presented as the number of patients }(\%) \text { unless noted otherwise. } \\
\text { Mean values are presented as the mean } \pm \mathrm{SD} \text {. } \\
\dagger \text { Only } 1021 \text { of the patients had preoperative images to measure the FOHR. } \\
\ddagger \text { Only } 1033 \text { of the patients had primary peritoneal shunt insertions. }\end{array}$} \\
\hline
\end{tabular}

\section{Time to Shunt Failure}

During the study period, we encountered 344 (33\%) CSF shunt failures. The failure was attributable to infection in 79 cases, for an overall shunt infection rate of $7.6 \%$. The mean time to shunt infection was 45 days with a range of 3-432 days. The remaining 265 failures were due to CSF shunt malfunction; 3 were treated with endoscopic third ventriculostomy and the rest underwent shunt revision. The mean time to failure was 344 days with a range of 1-932 days. The patients' time to failure was censored in $35(3.4 \%)$ cases for death not attributable to shunt malfunction, $30(2.9 \%)$ cases for out-of-network relocation, and $9(0.9 \%)$ cases for shunt removal without subsequent CSF diversion.

\section{Univariate Analyses of Risk Factors}

In Table 2, for the sake of clearer direct comparison, the cohort was divided into 2 groups: those with $(n=344)$ and those without $(n=692)$ CSF shunt failure during the study period; however, survival analyses (time to CSF shunt failure) were used to generate the unadjusted hazard ratios and confidence intervals. Age younger than 6 months at 
TABLE 2. Association between variables and the outcome of time to shunt malfunction

\begin{tabular}{|c|c|c|c|}
\hline Variable & $\begin{array}{c}\text { Shunt } \\
\text { Failure } \\
(n=344)^{*}\end{array}$ & $\begin{array}{c}\text { No Shunt } \\
\text { Failure } \\
(\mathrm{n}=692)^{*}\end{array}$ & $\begin{array}{c}\text { Unadjusted } \\
\text { HR }(95 \% \mathrm{Cl}) \dagger\end{array}$ \\
\hline \multicolumn{4}{|l|}{ Demographics } \\
\hline Age 0-6 mos & $223(64.8)$ & $354(51.2)$ & $1.5(1.2-1.9)$ \\
\hline Male sex & $205(59.6)$ & $377(54.5)$ & $1.2(0.96-1.5)$ \\
\hline \multicolumn{4}{|l|}{ Race } \\
\hline White & $209(60.8)$ & $446(64.5)$ & Referent \\
\hline African American & $50(14.5)$ & $102(14.7)$ & $1.1(0.8-1.4)$ \\
\hline Asian & $6(1.7)$ & $14(2.0)$ & $1.0(0.4-2.0)$ \\
\hline NH/PI/AI/AN & $2(0.6)$ & $8(1.2)$ & $0.5(0.1-1.6)$ \\
\hline Other/unknown & $77(22.4)$ & $122(17.6)$ & $1.3(1.0-1.7)$ \\
\hline \multicolumn{4}{|l|}{ Insurance } \\
\hline Public & $198(57.6)$ & $372(53.8)$ & $1.2(0.95-1.5)$ \\
\hline Private & $125(36.3)$ & $284(41.0)$ & Referent \\
\hline Other/self-pay & $21(6.1)$ & $36(5.2)$ & $1.4(0.8-2.2)$ \\
\hline \multicolumn{4}{|l|}{ HCRN Site } \\
\hline 1 & $62(18.0)$ & $192(27.8)$ & $0.7(0.5-1.0)$ \\
\hline 2 & $55(16.0)$ & $94(13.6)$ & $1.2(0.8-1.7)$ \\
\hline 3 & $116(33.7)$ & $161(23.3)$ & $1.2(0.9-1.6)$ \\
\hline 4 & $77(22.4)$ & $147(21.2)$ & Referent \\
\hline 5 & $25(7.3)$ & $71(10.3)$ & $0.8(0.5-1.2)$ \\
\hline 6 & $9(2.6)$ & $27(3.9)$ & $1.0(0.5-1.8)$ \\
\hline \multicolumn{4}{|l|}{ Clinical factors } \\
\hline \multicolumn{4}{|l|}{ Hydrocephalus etiology } \\
\hline Post-IVH/prematurity & $91(26.4)$ & $135(19.5)$ & $1.4(0.9-2.2)$ \\
\hline Myelomeningocele & $71(20.6)$ & $93(13.4)$ & $1.4(0.9-2.3)$ \\
\hline Aqueductal stenosis & $24(7.0)$ & $60(8.7)$ & Referent \\
\hline Posterior fossa tumor & $32(9.3)$ & 77 (11.1) & $1.1(0.7-1.9)$ \\
\hline Tumor, other & $25(7.3)$ & $58(8.4)$ & $1.2(0.7-2.0)$ \\
\hline \multirow{2}{*}{$\begin{array}{l}\text { Congenital communi- } \\
\text { cating }\end{array}$} & $17(4.9)$ & $63(9.1)$ & $0.6(0.3-1.1)$ \\
\hline & $13(3.8)$ & $25(3.6)$ & $1.1(0.5-2.1)$ \\
\hline Post-infectious & $14(4.1)$ & $35(5.1)$ & $0.9(0.5-1.8)$ \\
\hline $\begin{array}{l}\text { Post-head injury } \\
\text { Other }\end{array}$ & $57(16.6)$ & $146(21.1)$ & $1.0(0.6-1.6)$ \\
\hline Mean preop FOHR $\ddagger$ & $0.52 \pm 0.14$ & $0.56 \pm 0.11$ & $1.7(0.7-3.8)$ \\
\hline Gastrostomy tube & $38(11.1)$ & $62(9.0)$ & $1.2(0.9-1.7)$ \\
\hline Tracheostomy & $13(3.8)$ & $16(2.3)$ & $1.5(0.8-2.4)$ \\
\hline \multicolumn{4}{|l|}{ No. of CCCs } \\
\hline 0 & $239(69.5)$ & $488(70.5)$ & Referent \\
\hline 1 & $81(23.6)$ & $166(24.0)$ & $1.0(0.8-1.3)$ \\
\hline$\geq 2$ & $24(7.0)$ & $38(5.5)$ & $1.3(0.9-2.0)$ \\
\hline Neuromuscular CCC & $34(9.9)$ & $81(11.7)$ & $0.9(0.6-1.2)$ \\
\hline Cardiac CCC & $35(10.2)$ & $48(6.9)$ & $1.7(1.2-2.4)$ \\
\hline \multicolumn{4}{|l|}{ Surgeon factors } \\
\hline \multicolumn{4}{|l|}{ Surgeon experience } \\
\hline$<5 \mathrm{yrs}$ & $76(22.1)$ & $153(22.1)$ & $1.0(0.7-1.3)$ \\
\hline $5-9$ yrs & $112(32.6)$ & $249(36.0)$ & $0.8(0.7-1.1)$ \\
\hline$\geq 10 \mathrm{yrs}$ & $156(45.4)$ & $290(41.9)$ & Referent \\
\hline \multicolumn{4}{|l|}{ Surgeon vol at shunt } \\
\hline$<10$ shunts/yr & $208(60.5)$ & $416(60.1)$ & $0.9(0.6-1.4)$ \\
\hline $\begin{array}{l}10-19 \text { shunts/yr } \\
\geq 20 \text { shunts/yr }\end{array}$ & $106(30.8)$ & $218(31.5)$ & $0.9(0.6-1.4)$ \\
\hline
\end{tabular}

TABLE 2. Association between variables and the outcome of time to shunt malfunction (continued)

\begin{tabular}{|c|c|c|c|}
\hline Variable & $\begin{array}{c}\text { Shunt } \\
\text { Failure } \\
(n=344)^{*}\end{array}$ & $\begin{array}{c}\text { No Shunt } \\
\text { Failure } \\
(n=692)^{*}\end{array}$ & $\begin{array}{c}\text { Unadjusted } \\
\mathrm{HR}(95 \% \mathrm{Cl}) \dagger\end{array}$ \\
\hline \multicolumn{4}{|l|}{ Surgeon factors (continued) } \\
\hline \multicolumn{4}{|c|}{ Frameless stereotaxy } \\
\hline Yes & $14(4.1)$ & $35(5.1)$ & $0.9(0.5-1.6)$ \\
\hline No & $75(21.8)$ & $212(30.6)$ & Referent \\
\hline Unknown & $255(74.1)$ & $445(64.3)$ & NA \\
\hline Use of endoscope & $121(35.2)$ & $150(21.7)$ & $1.5(1.2-1.9)$ \\
\hline Use of ultrasound & $109(31.7)$ & $226(32.7)$ & $1.0(0.8-1.2)$ \\
\hline \multicolumn{4}{|l|}{ Shunt hardware } \\
\hline \multicolumn{4}{|l|}{ Shunt manufacturer } \\
\hline A & $141(41.0)$ & $292(42.2)$ & Referent \\
\hline$B$ & $139(40.4)$ & $224(32.4)$ & $1.2(0.9-1.5)$ \\
\hline C & $29(8.4)$ & $69(10.0)$ & $0.9(0.6-1.3)$ \\
\hline$D$ & $22(6.4)$ & $50(7.2)$ & $1.0(0.6-1.5)$ \\
\hline E & $5(1.5)$ & $31(4.5)$ & $0.4(0.1-0.9)$ \\
\hline Other & $8(2.3)$ & $26(3.8)$ & $0.6(0.3-1.2)$ \\
\hline \multicolumn{4}{|l|}{ Shunt programmability } \\
\hline Programmable & $49(14.2)$ & $128(18.5)$ & $0.8(0.6-1.1)$ \\
\hline Fixed & $292(84.9)$ & $553(79.9)$ & Referent \\
\hline $\begin{array}{l}\text { Other/unknown/no } \\
\text { valve }\end{array}$ & $3(0.9)$ & $11(1.6)$ & $0.6(0.2-1.7)$ \\
\hline AIC & $35(10.2)$ & $83(12.0)$ & $0.9(0.6-1.3)$ \\
\hline \multicolumn{4}{|l|}{ Other surgical factors } \\
\hline $\begin{array}{l}\text { Ventricular proximal } \\
\text { catheter }\end{array}$ & $323(93.9)$ & $645(93.2)$ & $1.0(0.6-1.4)$ \\
\hline \multicolumn{4}{|l|}{ Peritoneal entry } \\
\hline method§ & $193(56.6)$ & 396 (57.2) & Referent \\
\hline Minilap & $9(2.6)$ & $15(2.2)$ & $1.2(0.6-2.2)$ \\
\hline Laparoscopic & $124(36.4)$ & $238(34.4)$ & $1.0(0.8-1.3)$ \\
\hline Trocar & $15(4.4)$ & $43(6.2)$ & NA \\
\hline \multicolumn{4}{|l|}{ Not documented } \\
\hline $\begin{array}{l}\text { Mean case duration in } \\
\text { mins }\end{array}$ & $58 \pm 31$ & $58 \pm 31$ & $1.0(0.99-1.1)$ \\
\hline $\begin{array}{l}\text { Add-on/emergency case } \\
\text { priority }\end{array}$ & $126(36.6)$ & $257(37.1)$ & $1.1(0.9-1.3)$ \\
\hline \multicolumn{4}{|c|}{$\begin{array}{l}\text { NA }=\text { not applicable. } \\
* \text { Values are presented as the number of patients }(\%) \text { unless specified other- } \\
\text { wise. Mean values are presented as the mean } \pm \text { SD. } \\
\dagger \text { Bold values indicate significant association. } \\
\ddagger \text { Only } 1021 \text { of the patients had preoperative images to measure the FOHR. } \\
\S \text { Only } 1033 \text { of the patients had primary peritoneal shunt insertions. }\end{array}$} \\
\hline
\end{tabular}

initial shunt insertion (HR 1.5 [95\% CI 1.2-1.9]), a cardiac comorbidity (HR 1.7 [95\% CI 1.2-2.4]), and the use of the endoscope (HR 1.5 [95\% CI 1.2-1.9]) were associated with increased CSF shunt failure. The valve from shunt manufacturer "E" was found to be associated with a decreased hazard (HR 0.4 [95\% CI 0.1-0.9]) of CSF shunt failure on univariate analysis. The etiology of hydrocephalus, the number of CCCs; use of the intraoperative ultrasound, AICs, and programmable valves; abdominal entry method; case priority; and all other variables were not associated with CSF shunt failure. Although "Other/ Unknown" race was associated with CSF shunt failure, 
this specific category was preferentially populated with a single site at which its IRB denied collection of race data, as discussed in the Methods. However, HCRN site was not associated with time to CSF shunt failure.

\section{Multivariate Survival Analyses of Risk Factors}

All variables found to have a significant univariate association with time to CSF shunt failure as well as those identified a priori by the HCRN Investigator Committee were tested in the multivariable Cox proportional hazards model (Table 3). The only risk factors found to have an independent association with time to first CSF shunt failure were patient age $<6$ months (adjusted HR 1.6 [1.1-2.1]), a cardiac CCC (adjusted HR 1.4 [1.0-2.1]), and the intraoperative use of the endoscope (adjusted HR 1.9 [1.2-2.9]). The survival curves for each of these 3 risk factors are demonstrated in Fig. 1. The etiology of the hydrocephalus,

TABLE 3. Multivariate Cox proportional hazard modeling for the association of independent risk factors and the outcome of time to shunt malfunction*

\begin{tabular}{|c|c|c|}
\hline Variables at Study & $\begin{array}{l}\text { Adjusted HR } \\
(95 \% \mathrm{Cl})\end{array}$ & $p$ Value \\
\hline Age 0-6 mos & $1.6(1.1-2.1)$ & 0.006 \\
\hline \multicolumn{3}{|l|}{ Hydrocephalus etiology } \\
\hline Post-IVH/prematurity & $1.3(0.8-2.1)$ & 0.3 \\
\hline Myelomeningocele & $1.4(0.9-2.3)$ & 0.2 \\
\hline Aqueductal stenosis & Referent & Referent \\
\hline Posterior fossa tumor & $1.7(0.9-3.2)$ & 0.08 \\
\hline Tumor, other & $1.6(0.8-3.0)$ & 0.2 \\
\hline Congenital communicating & $0.7(0.4-1.3)$ & 0.2 \\
\hline Postinfectious & $1.1(0.5-2.2)$ & 0.8 \\
\hline Post-head injury & $1.4(0.7-2.8)$ & 0.4 \\
\hline Other & $1.0(0.6-1.6)$ & 0.9 \\
\hline \multicolumn{3}{|l|}{ HCRN site } \\
\hline 1 & $0.8(0.6-1.2)$ & 0.2 \\
\hline 2 & $1.3(0.9-1.9)$ & 0.2 \\
\hline 3 & $0.5(0.3-1.0)$ & 0.06 \\
\hline 4 & Referent & Referent \\
\hline 5 & $0.6(0.3-1.2)$ & 0.1 \\
\hline 6 & $0.7(0.3-1.7)$ & 0.4 \\
\hline \multicolumn{3}{|l|}{ Shunt manufacturer } \\
\hline A & Referent & Referent \\
\hline$B$ & $1.6(0.8-2.9)$ & 0.2 \\
\hline C & $0.9(0.5-1.6)$ & 0.7 \\
\hline$D$ & $1.2(0.7-2.0)$ & 0.5 \\
\hline $\mathrm{E}$ & $0.5(0.2-1.1)$ & 0.1 \\
\hline Other & $0.8(0.3-1.8)$ & 0.6 \\
\hline \multicolumn{3}{|l|}{ Shunt programmability } \\
\hline Programmable & $(0.6-1.9)$ & 1.0 \\
\hline Fixed & Referent & Referent \\
\hline Other/unknown/no valve & $1.4(0.3-5.9)$ & 0.7 \\
\hline Cardiac CCC & $1.4(1.0-2.1)$ & 0.05 \\
\hline Use of endoscope & $1.9(1.2-2.9)$ & 0.003 \\
\hline Preop FOHR† & $1.5(0.5-4.4)$ & 0.5 \\
\hline
\end{tabular}

* Bold values indicate significant independent association with time to first shunt failure.

† Only 1021 of the patients had preoperative images to measure the FOHR. the HCRN site at which the shunt was placed, the manufacturer of the CSF shunt, programmable CSF shunts, and preoperative ventricle size (FOHR) were not found to be significant independent risk factors for shunt failure.

\section{Discussion}

We present a multicenter prospective cohort study from the HCRN examining the risk factors for CSF shunt failure (malfunction and infection) in 1036 children undergoing initial placement of a CSF shunt for hydrocephalus. Our cohort's first CSF shunts had a $33.2 \%$ failure rate during the study period; 79 of these 344 failures (23\%) of
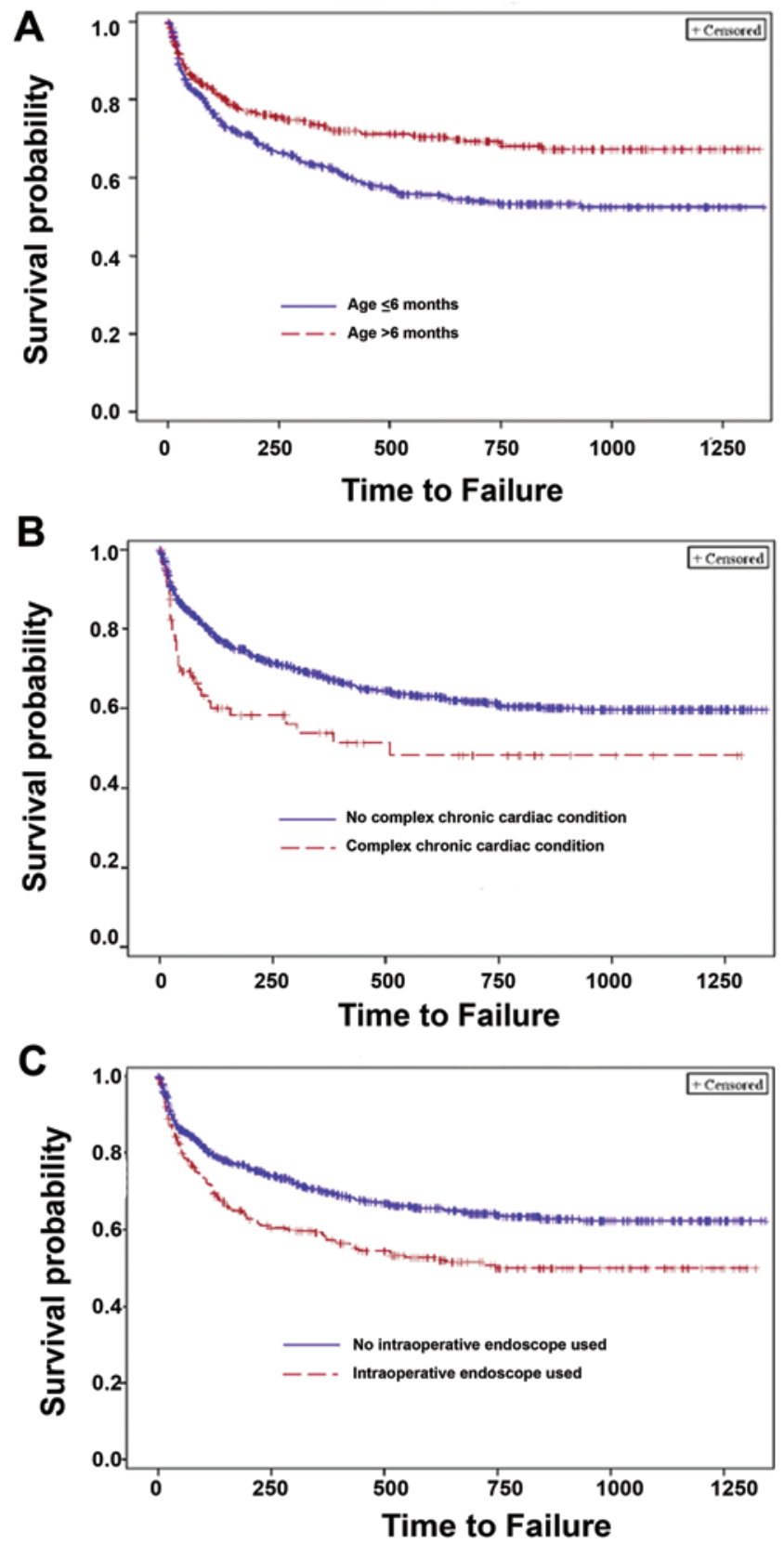

FIG. 1. Survival curves (time to first shunt failure) for 3 risk factors shown to be significant on multivariate analysis: age $<6$ months (A), cardiac CCC (B), and use of the intraoperative endoscope (C). Figure is available in color online only. 
these presented as a CSF shunt infection. We found that age younger than 6 months, a cardiac comorbidity, and the use of the endoscope at the time of initial CSF shunt placement all incurred an increased risk of failure. Notably, the etiology of hydrocephalus, the type of valve used, and the use of other surgical adjuncts (frameless stereotaxy and ultrasound) were not associated with CSF shunt survival.

Age and etiology of hydrocephalus are intertwined as certain etiologies are more apt to occur at specific ages; for instance, post-IVH secondary to prematurity occurs in infants, while most tumor-related hydrocephalus occurs in older children. In a study of 839 children, Tuli et al. ${ }^{23}$ found both etiology and age younger than 1 year at initial shunt insertion were risk factors for higher CSF shunt failure. In a cohort of 554 children, Simon et al. ${ }^{21}$ found that the etiology of post-IVH secondary to prematurity (adjusted OR 2.2 [95\% CI 1.1-4.5]) was a risk factor for initial CSF shunt survival but that age was not. Piatt and Carlson ${ }^{17}$ found age $(p<0.001)$ but not etiology to be a risk factor for pediatric CSF shunt failure. These 3 studies with large sample sizes illustrate the uncertainty that previously existed in the medical literature; however, they were limited as single-center studies and/or being retrospective in nature. Like Piatt and Carlson, we found that only age $(<6$ months) and not etiology was a determinant of CSF shunt survival. Our larger, multicenter, prospective design more definitively untangles age from etiology and quantifies its effect on shunt failure (adjusted HR 1.6 [1.1-2.1]).

Our finding that a preexisting cardiac comorbidity had a negative impact on CSF shunt survival is somewhat novel. We could find only one other report of this linkage: Kebriaei et al. ${ }^{8}$ prospectively followed 270 children younger than 1 year after an initial CSF shunt placement and found those with preshunt cardiac surgery had greater risk of CSF shunt infection $(p=0.001)$. Our definition of cardiac comorbidity was broader than that of Kebriaei et al., as evidenced by our rate of $11.1 \%$ versus theirs of $4.1 \%$. We used the CCC methodology described by Feudtner et al., ${ }^{4}$ which includes heart and great vessel malformations, cardiomyopathies, and conduction disorders, and dysrhythmias. The association with CSF shunt failure was specific to cardiac disease and was not a marker for overall illness, as none of the other CCC indicators were significant. The explanation for this phenomenon is unclear and demands further study but may be related to immunodeficiency, repeated cardiac hospitalizations and surgeries, or complications secondary to anticoagulation.

The endoscope is frequently used intraoperatively to achieve and confirm "ideal" placement of the proximal (ventricular) catheter away from the choroid plexus with the goal of prolonging CSF shunt survival; however, we found that the endoscope actually increased the risk of CSF shunt failure. The endoscope was used for initial shunt insertion routinely by some surgeons, intermittently by others, and never by the majority; however, the endoscope variable remained independently statistically significant despite adjusting for site, etiology, shunt manufacturer and programmability, cardiac CCC, and preoperative ventricle size. Our finding is consistent with those of the Endoscopic Shunt Insertion Trial, which was a multicenter randomized, controlled study examining first CSF shunts in 393 children with newly diagnosed hydrocephalus. Not only did the authors find no benefit in shunt survival with the use of the endoscope $(p=0.09)$, but the trend for shunt failure at 1 year was higher with the endoscope (42\%) than without (34\%). This failure rate appears to be driven by shunt malfunction rather than shunt infection as the endoscope was not significantly associated (OR 1.45 [0.97-2.13]) with shunt infection in a previous HCRN study. ${ }^{18}$ Our study found that this harm was specific to the endoscope as the other surgical adjuncts used to direct the proximal catheters (ultrasound and frameless stereotaxy) were associated with neither CSF shunt failure nor a trend toward diminished shunt survival. Considering the evidence, we would not recommend the routine use of the endoscope for the insertion of a child's initial CSF shunt.

We found that no single CSF shunt valve had superior shunt survival over another in terms of the shunt manufacturer, programmability, or specific shunt types (data not shown). These data expand on and confirm existing Class I evidence. The Shunt Design Trial by Drake et al. ${ }^{3}$ had a very comparable sample to our study and demonstrated no significant difference in CSF shunt failure between the 3 most prevalent shunt valves, which are still in use today $(p=0.24)$. Therefore, we cannot recommend any one CSF shunt valve over another for initial CSF shunt insertion.

This study has several limitations. The HCRN is a research network consisting of 9 large North American pediatric neurosurgery centers ( 6 of which participated in this specific project) with several active protocols all centered on hydrocephalus and CSF shunting. Sites within the network comply with specific treatment algorithms for CSF shunt surgery and the care of premature infants with IVH. Therefore, despite this being a multicenter and multinational study, generalizability to smaller or non-tertiary level practices or those with differing care algorithms may be limited. We attempted to minimize confounder bias by utilizing wide expertise within the HCRN's Investigator Committee to a priori identify important variables to examine and by gathering a large cohort to maximize the number of variables at study. As with any nonrandomized study, however, important unidentified or uncollected confounding variables may have biased our findings. Data were only collected on subsequent CSF shunt surgery or follow-up at the original treatment HCRN site; therefore, any out-ofnetwork surgery or follow-up may have biased our results. We did record and censor 30 (2.9\%) patients for relocation from their original treating site during the study period.

\section{Conclusions}

In this large multicenter, prospective cohort study from the HCRN, we found that age younger than 6 months, a preexisting cardiac comorbidity, and the use of the intraoperative endoscope for proximal catheter placement were independently associated with higher risks of initial CSF shunt failure. Previously suggested risk factors such as the etiology of hydrocephalus, the treating site, other adjuncts for directing proximal catheter placement, and valve types did not have a significant effect on initial CSF shunt survival. The routine use of the endoscope for initial CSF shunt insertion is not recommended. Future studies exam- 
ining initial pediatric CSF shunt failure should adjust for age and cardiac comorbidity as defined by a cardiac CCC.

\section{Appendix \\ HCRN Members}

The HCRN currently consists of the following clinical centers and investigators:

Primary Children's Hospital, University of Utah (J Kestle, M Walker, J Riva-Cambrin); Children's Hospital of Alabama, University of Alabama at Birmingham (J Oakes, C Rozzelle); Hospital for Sick Children, University of Toronto (J Drake, A Kulkarni); Texas Children's Hospital, Baylor College of Medicine (T Luerssen, W Whitehead); Seattle Children's Hospital, University of Washington (S Browd, T Simon); Children's Hospital of Pittsburgh, University of Pittsburgh (M Tamber); St. Louis Children's Hospital, Washington University in St. Louis (D Limbrick); Monroe Carell Jr. Children's Hospital at Vanderbilt, Vanderbilt University Medical Center (J Wellons, C Shannon); British Columbia Children's Hospital, University of British Columbia (D Cochrane); HCRN Data Coordinating Center, Department of Pediatrics, University of Utah (R Holubkov).

\section{Acknowledgments}

We thank the Hydrocephalus Association for their continued support of the HCRN, and Kristin Kraus, MSc, for editorial assistance with the paper.

The HCRN has been funded by private philanthropy and National Institute of Neurological Disorders and Stroke (NINDS) Grant No. 1RC1NS068943-01.

Dr. Simon is supported by Award K23NS062900 from the National Institute of Neurological Disorders and Stroke, the Child Health Corporation of America via the Pediatric Research in Inpatient Setting Network Executive Council, and the Seattle Children's Center for Clinical and Translational Research.

None of the sponsors participated in design and conduct of the study; collection, management, analysis, and interpretation of the data; or preparation, review, or approval of the manuscript. Its contents are solely the responsibility of the authors and do not necessarily represent the official view of the sponsors.

The authors would like to thank their colleagues who kindly agreed to participate in this HCRN project and allow collection of patient data for the purpose of this publication: Douglas Brockmeyer, Rob Bollo, Jeff Blount, James Johnston, Brandon Rocque, Leslie Ackacpo-Satchivi, Peter Dirks, James Rutka, Michael Taylor, Daniel Curry, Robert Dauser, Andrew Jea, Sandi Lam, Richard Ellenbogen, Jeffery Ojemann, Amy Lee, Anthony Avellino, R. Aaron Robison, Ian Pollack, Stephanie Greene, Elizabeth Tyler-Kabara, T. S. Park, Jeffrey Leonard, Matthew Smyth, Noel Tulipan, Robert Naftel, Ash Signhal, Paul Steinbok.

In addition, this work would not have been possible without the outstanding support of the dedicated personnel at each clinical site and the data coordinating center. Special thanks goes to Tracey Bach (Salt Lake City), Anastasia Arynchyna (Birmingham), Homa Ashrafpour (Toronto), Sheila Ryan (Houston), Amy Anderson (Seattle), Arlene Luther (Pittsburgh), Deanna Mercer (St. Louis), Angela Davis, (Nashville), Ross Hengel (British Columbia), and Marcie Langley, Nichol Nunn, and Tyler Hunt (Utah Data Coordinating Center). The authors thank them for their hard work and contributions to the HCRN.

\section{References}

1. Brydon HL, Hayward R, Harkness W, Bayston R: Does the cerebrospinal fluid protein concentration increase the risk of shunt complications? Br J Neurosurg 10:267-273, 1996

2. Chittiboina P, Pasieka H, Sonig A, Bollam P, Notarianni C, Willis BK, et al: Posthemorrhagic hydrocephalus and shunts: what are the predictors of multiple revision surgeries? J Neurosurg Pediatr 11:37-42, 2013

3. Drake JM, Kestle JR, Milner R, Cinalli G, Boop F, Piatt J Jr, et al: Randomized trial of cerebrospinal fluid shunt valve design in pediatric hydrocephalus. Neurosurgery 43:294-305, 1998

4. Feudtner C, Christakis DA, Connell FA: Pediatric deaths attributable to complex chronic conditions: a population-based study of Washington State, 1980-1997. Pediatrics 106:205209, 2000

5. Fulkerson DH, Vachhrajani S, Bohnstedt BN, Patel NB, Patel AJ, Fox BD, et al: Analysis of the risk of shunt failure or infection related to cerebrospinal fluid cell count, protein level, and glucose levels in low-birth-weight premature infants with posthemorrhagic hydrocephalus. J Neurosurg Pediatr 7:147-151, 2011

6. Hommelstad J, Mads $\emptyset$ A, Eide PK: Significant reduction of shunt infection rate in children below 1 year of age after implementation of a perioperative protocol. Acta Neurochir (Wien) 155:523-531, 2013

7. Jeelani NU, Kulkarni AV, Desilva P, Thompson DN, Hayward RD: Postoperative cerebrospinal fluid wound leakage as a predictor of shunt infection: a prospective analysis of 205 cases. Clinical article. J Neurosurg Pediatr 4:166-169, 2009

8. Kebriaei MA, Shoja MM, Salinas SM, Falkenstrom KL, Sribnick EA, Tubbs RS, et al: Shunt infection in the first year of life. J Neurosurg Pediatr 12:44-48, 2013

9. Kestle JR, Drake JM, Cochrane DD, Milner R, Walker ML, Abbott R III, et al: Lack of benefit of endoscopic ventriculoperitoneal shunt insertion: a multicenter randomized trial. J Neurosurg 98:284-290, 2003

10. Kestle JR, Riva-Cambrin J, Wellons JC III, Kulkarni AV, Whitehead WE, Walker ML, et al: A standardized protocol to reduce cerebrospinal fluid shunt infection: the Hydrocephalus Clinical Research Network Quality Improvement Initiative. J Neurosurg Pediatr 8:22-29, 2011

11. Kulkarni AV, Drake JM, Armstrong DC, Dirks PB: Measurement of ventricular size: reliability of the frontal and occipital horn ratio compared to subjective assessment. Pediatr Neurosurg 31:65-70, 1999

12. Kulkarni AV, Drake JM, Lamberti-Pasculli M: Cerebrospinal fluid shunt infection: a prospective study of risk factors. J Neurosurg 94:195-201, 2001

13. Kulkarni AV, Riva-Cambrin J, Butler J, Browd SR, Drake JM, Holubkov R, et al: Outcomes of CSF shunting in children: comparison of Hydrocephalus Clinical Research Network cohort with historical controls. J Neurosurg Pediatr 12:334-338, 2013

14. Levitt MR, O'Neill BR, Ishak GE, Khanna PC, Temkin $\mathrm{NR}$, Ellenbogen RG, et al: Image-guided cerebrospinal fluid shunting in children: catheter accuracy and shunt survival. J Neurosurg Pediatr 10:112-117, 2012

15. O’Hayon BB, Drake JM, Ossip MG, Tuli S, Clarke M: Frontal and occipital horn ratio: A linear estimate of ventricular size for multiple imaging modalities in pediatric hydrocephalus. Pediatr Neurosurg 29:245-249, 1998

16. Parker SL, Attenello FJ, Sciubba DM, Garces-Ambrossi GL, Ahn E, Weingart J, et al: Comparison of shunt infection incidence in high-risk subgroups receiving antibiotic-impregnated versus standard shunts. Childs Nerv Syst 25:77-83, 85, 2009

17. Piatt JH Jr, Carlson CV: A search for determinants of cerebrospinal fluid shunt survival: retrospective analysis of a 14-year institutional experience. Pediatr Neurosurg 19:233242, 1993

18. Simon TD, Butler J, Whitlock KB, Browd SR, Holubkov R, Kestle JR, et al: Risk factors for first cerebrospinal fluid shunt infection: findings from a multi-center prospective cohort study. J Pediatr 164:1462-1468, 1468.e1-1468.e2, 2014

19. Simon TD, Hall M, Riva-Cambrin J, Albert JE, Jeffries HE, Lafleur B, et al: Infection rates following initial cerebrospinal 
fluid shunt placement across pediatric hospitals in the United States. J Neurosurg Pediatr 4:156-165, 2009

20. Simon TD, Riva-Cambrin J, Srivastava R, Bratton SL, Dean JM, Kestle JR: Hospital care for children with hydrocephalus in the United States: utilization, charges, comorbidities, and deaths. J Neurosurg Pediatr 1:131-137, 2008

21. Simon TD, Whitlock KB, Riva-Cambrin J, Kestle JR, Rosenfeld M, Dean JM, et al: Association of intraventricular hemorrhage secondary to prematurity with cerebrospinal fluid shunt surgery in the first year following initial shunt placement. J Neurosurg Pediatr 9:54-63, 2012

22. Simon TD, Whitlock KB, Riva-Cambrin J, Kestle JR, Rosenfeld M, Dean JM, et al: Revision surgeries are associated with significant increased risk of subsequent cerebrospinal fluid shunt infection. Pediatr Infect Dis J 31:551-556, 2012

23. Tuli S, Drake J, Lawless J, Wigg M, Lamberti-Pasculli M: Risk factors for repeated cerebrospinal shunt failures in pediatric patients with hydrocephalus. J Neurosurg 92:31-38, 2000

24. Wilson TJ, Stetler WR Jr, Al-Holou WN, Sullivan SE: Comparison of the accuracy of ventricular catheter placement using freehand placement, ultrasonic guidance, and stereotactic neuronavigation. J Neurosurg 119:66-70, 2013

\section{Disclosures}

Dr. Browd reports that he has ownership in Aqueduct Neuroscience Inc., Aqueduct Critical Care Inc., and Navisonics Inc.

\section{Author Contributions}

Conception and design: Riva-Cambrin, Kestle, Holubkov, Butler, Kulkarni, Simon. Acquisition of data: Riva-Cambrin, Kulkarni, Whitehead, Wellons, Limbrick, Browd. Analysis and interpretation of data: all authors. Drafting the article: Riva-Cambrin. Critically revising the article: all authors. Reviewed submitted version of manuscript: Riva-Cambrin, Kestle, Holubkov, Butler, Kulkarni, Drake, Whitehead, Wellons, Shannon, Tamber, Rozzelle, Browd, Simon. Approved the final version of the manuscript on behalf of all authors: Riva-Cambrin. Statistical analysis: Riva-Cambrin, Kestle.

\section{Correspondence}

Jay Riva-Cambrin, Department of Neurosurgery, Division of Pediatric Neurosurgery, Primary Children's Hospital, 100 N. Mario Capecchi Dr., Salt Lake City, UT 84113. email: jay.rivacambrin@hsc.utah.edu. 